\title{
A concepção de Estado no debate sobre política educacional: uma análise dos trabalhos apresentados no GT5 da ANPEd (2000-2010)
}

\author{
Armando C. Arosa
}

\begin{abstract}
Resumo
O objetivo deste trabalho é apresentar uma análise acerca da concepção de Estado que fundamenta o debate que trata das políticas educacionais no Brasil. O texto é parte dos resultados da pesquisa que buscou identificar os principais traços teóricos que caracterizam a produção referenciada pela Associação Nacional de Pós-graduação e Pesquisa em Educação - ANPEd, por meio do GT5 - Estado e Políticas Educacionais, entre 2000 e 2010. A análise aqui apresentada encontra-se no contexto de uma investigação que propõe uma reflexão que faça emergir em que circunstâncias históricas, sociais, econômicas e políticas se desenvolvem as relações estabelecidas entre os sujeitos e as instituições envolvidos na produção acadêmico-científica brasileira, de modo a contribuir para a construção de conhecimento acerca dos processos de consolidação da pesquisa educacional no Brasil. Nessa linha, a pesquisa também abordou temas como a relação público/privado; gestão, participação e autonomia; federalismo; descentralização; municipalização; e financiamento da educação - que deixam de ser apresentados aqui em função do objetivo e dos limites deste artigo - como constituintes de um conjunto de fundamentos que orientam a discussão sobre as políticas educacionais no Brasil.
\end{abstract}

Palavras-chave: Estado. Políticas Educacionais. Epistemologia de Políticas.

\footnotetext{
* Doutor em Educação Universidade Federal do Rio de Janeiro (UFRJ). Professor do Departamento de Administração Educacional da Faculdade de Educação da Universidade Federal do Rio de Janeiro (UFRJ).
} 
O objetivo deste trabalho é apresentar uma análise acerca da concepção de Estado que fundamenta o debate que trata das políticas educacionais no Brasil. O texto é parte dos resultados da pesquisa que buscou identificar os principais traços teóricos que caracterizam a produção referenciada pela Associação Nacional de Pós-graduação e Pesquisa em Educação (ANPEd), por meio do GT5 Estado e Políticas Educacionais, entre 2000 e 2010. A análise aqui apresentada encontra-se no contexto de uma investigação que propõe uma reflexão que faça emergir em que circunstâncias históricas, sociais, econômicas e políticas se desenvolvem as relações estabelecidas entre os sujeitos e as instituições envolvidos na produção acadêmico-científica brasileira, de modo a contribuir para a construção de conhecimento acerca dos processos de consolidação da pesquisa educacional no Brasil. Nessa linha, a pesquisa também abordou temas como a relação público/privado; gestão, participação e autonomia; federalismo; descentralização; municipalização; e financiamento da educação - que deixam de ser apresentados aqui em função do objetivo e dos limites deste artigo - como constituintes de um conjunto de fundamentos que orientam a discussão sobre as políticas educacionais no Brasil.

O debate sobre a origem, constituição, desenvolvimento, função e outras características sobre o Estado é intenso e tem sido presente na história do pensamento político desde a antiguidade. Não se pretende fazer um inventário crítico acerca do debate travado no âmbito da produção acadêmica mais amplamente considerada, mas o que se fará nesse espaço corresponde a uma busca por identificar a partir de que premissas são debatidas, nos textos estudados nesta pesquisa, as questões relativas à constituição do Estado, seus processos e as relações que estabelece com a sociedade civil.

No conjunto dos temas que aparecem na fundamentação da análise sobre políticas educacionais, o Estado surge como principal elemento a partir do qual se pode compreender as relações estabelecidas. A principal razão que se pode atribuir a esse fato é a concepção dominante de que ao Estado é conferida centralidade na elaboração e implementação das políticas educacionais. Mesmo nos trabalhos em que aparecem análises sobre a influência de agentes internacionais (Banco Mundial, Organização para a Educação, a Ciência e a Cultura das Nações Unidas - Unesco, entre outros), ou de agentes do chamado terceiro setor, o Estado é considerado como o responsável pela política educacional e é com foco em suas ações que as análises são realizadas, ainda que reagindo sob a indução de agentes da sociedade civil que representam o capital (concepção também presente nesses trabalhos).

De modo geral, implícita ou explicitamente, essa visão aparece na perspectiva de compreender a política como: 
[...] o arcabouço estrutural configurado nas relações do Estado com a sociedade civil onde as demandas e pressões exercidas pelo conjunto dos cidadãos associam-se aos interesses de ordem econômica e política definindo linhas de ações institucionais. Sendo assim, na configuração estrutural das políticas públicas estão em jogo, não só a vontade ou os interesses governamentais mas, também, formas de regulação que cada sociedade desenvolve e coloca em prática a partir do seu estágio de desenvolvimento e conscientização política. (SANTIAGO, 2000, p. 2).

Emergem dos trabalhos apresentados duas concepções básicas sobre a natureza e a função do Estado. A concepção mais amplamente tomada como preceito é a de "Estado histórico, concreto, de classe, e, nesse sentido, Estado máximo para o capital, já que, no processo de correlação de forças em curso, é o capital que detém a hegemonia" (PERONI, 2000, p. 1).

Pode-se dizer que esta concepção deriva da perspectiva que compreende o Estado como expressão de uma sociedade organizada em classes, de modo tal que a história se processa por meio da luta travada entre elas. Essa concepção, que se mostra como tendência teórica organizadora do debate realizado no GT - 5, traduz-se, de modo geral, a partir das premissas apontadas acima, em dois princípios.

O primeiro princípio diz respeito ao lugar estratégico ocupado pelo Estado na manutenção do sistema capitalista de produção, tanto no sentido de criar e manter as condições materiais de seu funcionamento, quanto na função de reprodução das condições ideológica para aceitação das premissas fundamentais que apontam o capitalismo como condição a priori para sustentação do Estado Democrático de Direito. O segundo princípio refere-se às lutas travadas na sociedade como um todo, mesmo por dentro dos aparelhos de Estado (no âmbito do Poder Legislativo, por exemplo), que apontam para uma assimetria que concentra maior força nas camadas sociais vinculadas ao capital.

Esses princípios fundamentam e orientam os diagnósticos realizados acerca da conjuntura que, segundo grande parte dos trabalhos, localiza a gênese das políticas educacionais na crise, ora centrada no denominado Estado capitalista, ora centrada na organização produtiva, significando uma crise do capitalismo. Essa é a base para o contra-argumento às explicações produzidas pelo neoliberalismo, que situam, de modo inverso, a origem da crise no Estado de Previdência que, segundo os teóricos trazidos como referência dessa corrente de pensamento (Hayek, principalmente), causou o desequilíbrio do sistema econômico.

De maneira expressa, ou implicitamente, esses princípios aparecem nos pressupostos a partir dos quais se fará a análise das políticas públicas, permeando o debate acerca do capitalismo, tanto como recurso para apontar o caráter deletério dessa forma de organização do sistema de produção 
material quanto para justificar o posicionamento contrário às posições ideológicas que lhe dão sustentação (CATTANI et al., 2000; SIQUEIRA, 2001; NEVES, 2004; FREITAS, 2005; CARVALHO, 2007; VOLPE, 2007; GIL, 2008, entre outros). De modo geral, essa estratégia discursiva situa o capitalismo a partir do papel do Estado em sua conformação atual, abordando aspectos político-econômicos. Ou seja, um movimento coloca o Estado como figura central na manutenção do capitalismo, portanto integra a delimitação do seu conceito; e outro movimento que, ao conceituar Estado, o faz a partir da relação entre mercado e Estado. Essa tendência, então, coloca na base da definição do conceito de Estado a relação entre o sistema produtivo e o sistema de regulação jurídica e ideológica. Assim, a base sobre a qual se constrói o conceito de capitalismo e a análise sobre sua relação com as políticas educacionais repousa na interpretação crítica acerca dos processos macroeconômicos, aparecendo, amplamente utilizada como premissa, a relação de causalidade entre crise do capitalismo e Estado, seja este último como causa da crise ou como fonte para sua solução; nos dois casos, como alvo de crítica, por um lado do pensamento neoliberal e por outro dos que lhe fazem oposição.

Essa análise também é desenvolvida a partir do desdobramento dessa premissa como forma de compreender a tensão entre capital e trabalho por meio das mudanças ocorridas a partir da reestruturação produtiva, com seu foco voltado para as alterações nas relações de trabalho e na formação do trabalhador.

Como registram Catani, Oliveira e Dourado (2000, p. 1) acerca das análises que circulam sobre o tema:

[...] pode-se dizer, grosso modo, que o fio condutor destas análises de estudiosos da área continua sendo o das relações capital-trabalho, evidentemente que numa fase singular da história do capitalismo. Além disso, é possível observar que há, nessas análises, esforços no sentido de compreender as transformações no mundo do trabalho e, conseqüentemente, nos processos de produção, de organização e de formação profissional.

Nessa mesma linha, a perspectiva adotada para abordar o conceito de capitalismo - presente nos trabalhos - é a de apresentá-lo a partir dos processos pelos quais vem passando nos últimos 40 anos. Os processos a que se fazem mais referências tomam como premissa essa necessidade de superação da crise e que aparecem, dispersos, muitas vezes sem referências às fontes, por meio de diversos traços: ideia de mercado pautada pela visão neoliberal; necessidade de inovação tecnológica como forma de maximizar o processo de acumulação de capital; autonomização do sistema financeiro; flexibilização das relações trabalhistas; empregabilidade; desemprego estrutural; internacionalização das empresas, 
que passam a operar de forma articulada com os organismos políticos e de financiamento para induzir as políticas de Estado; terceirização; privatização; precarização do trabalho; dentre outros, novamente como alvos de crítica.

A outra perspectiva a partir da qual se vai debater sobre a dimensão substantiva do Estado, a saber, sua definição e conteúdo, é a que se ancora nas concepções neoliberais, que buscam explicá-lo a partir da tensão entre as liberdades individuais a serem garantidas e a necessidade de um ente a quem se atribui a neutralidade necessária para que, como agente de controle e coerção, possa fazer uso legítimo da força. Esses traços passam, na acepção mais utilizada, a fundamentar o modelo de democracia liberal e a servir de base para a noção de Direito.

Para Vera Peroni (2000, p. 4):

A lógica do pensamento neoliberal está na tensão entre a liberdade individual e a democracia. Para Hayek (1984), a maximização da liberdade está em se proteger o sistema de mercado, necessário e suficiente para a existência da liberdade individual.

Assim, o mercado deve ser protegido contra o Estado e, também, da tirania das maiorias. Para a teoria política neoliberal, o cidadão, através do voto, decide sobre bens que não são seus, gerando conflitos com os proprietários, pois este sistema consiste-se em uma forma de distribuição de renda. Hayek (1984) denuncia que a democracia faz um verdadeiro saque à propriedade alheia. Portanto, como, em muitos casos, não se pode suprimir, totalmente, a democracia (voto, partidos), o esforço dá-se no sentido de esvaziar seu poder.

Nessa linha de argumentação, o mercado assume importância na organização das relações econômicas e sociais, fazendo vir a relevo a ideia de um Estado que não intervenha na vida dos indivíduos sob alegação de produzir efeitos maléficos para a sociedade. Assim, a crítica ao Estado de Previdência se dá, não apenas com base em razões econômicas, mas também na perspectiva éticopolítica (ou ideológica). Resultante, portanto, desses pressupostos, essa crítica localiza no Estado a razão primeira para a crise e produz ações políticas que objetivam disparar no ordenamento econômico mundial uma série de mudanças que passam a ser urdidas no sentido de se manterem as condições de funcionamento do capitalismo, que a partir daquele momento ganha alguns novos traços.

As políticas educacionais, na concepção de parte majoritária dos trabalhos estudados nesta pesquisa, são construídas a partir das reformas promovidas com base no diagnóstico produzido por essa corrente político-ideológica. Para Peroni (2000. p. 1):

Parte-se do pressuposto de que a origem das mudanças propostas para a educação na década de 90 tem como substrato um diagnóstico que identifica a crise do capitalismo como resultado da crise do Estado. Esse diagnóstico é comungado por duas orientações 
políticas: o Neoliberalismo e a Terceira Via. Em ambas, a crítica à ineficácia do Estado de Bem-Estar Social é um dos aspectos passíveis de serem generalizados.

Para a teoria neoliberal não é o capitalismo que está em crise, mas o Estado. Portanto, a estratégia adotada para a superação da crise seria a reforma no Estado por meio da diminuição de sua atuação. Em linhas gerais, para essa perspectiva, duas causas levaram à crise do Estado: a primeira deve-se a um excessivo gasto governamental gerado pela permanente necessidade de se legitimar por meio do atendimento às demandas da população por políticas sociais, o que provocou a crise fiscal. Além disso, para esta lógica, as políticas sociais, por se constituírem em mecanismos de distribuição da riqueza, confrontavam-se com o direito à propriedade privada, razão pela qual gerariam distorções indesejáveis nas sociedades de mercado e deveriam ser suprimidas.

A segunda causa encontrava-se no papel regulador desempenhado pelo Estado na esfera econômica, prática que atrapalhava o livre andamento do mercado. Como condição para a superação de tais causas, o neoliberalismo atribuía ao mercado a capacidade de superar as falhas do Estado, inclusive tomando de empréstimo a lógica mercantil e adotando-a na gestão de instâncias estatais, como forma de torná-las mais eficientes e produtivas. (PERONI, 2000. p. 1).

Para que se possa ter condições ideais, reduzindo a participação do Estado em áreas indesejáveis, bem como produzir os mecanismos para que seus custos sejam reduzidos e assim se ganhe em produtividade, são propostas reformas na configuração do Estado. Esses elementos aparecem nos textos como instrumentos para descrever o processo de constituição e de reorganização do Estado brasileiro frente às demandas desse novo ordenamento político-econômico e jurídico-institucional do capitalismo $^{1}$, na fase em que passa a assumir caráter hegemônico, segundo a visão dos trabalhos, a partir da denominada crise dos anos de 1970 e 1980.

Com relação, portanto, às reformas educacionais promovidas pelo Estado brasileiro, as razões comumente encontradas tomam como base análises do cenário econômico internacional, relacionandoo às transformações na organização do sistema produtivo. Como situa Olgaises Maués (2005, p. 1):

As reformas educacionais implementadas nos anos de 1990 e no início da atual década, no Brasil, procuraram traduzir as demandas postas pela lógica do capital, respondendo às exigências emanadas dos organismos internacionais. A crise mundial do Estado capitalista, que se manifestou de forma evidente a partir dos anos de 1970, gerou a necessidade de se buscar saídas que permitissem a retomada dos objetivos de crescimento econômico, propiciando o surgimento de um novo modelo de acumulação, denominado por HARVEY (1998) de "acumulação flexível".

Nessa acepção, convergindo com a tendência de tomar o Estado como centro de decisões, esta centralidade se pauta no caráter regulador que é atribuído ao Estado e na capacidade que as reformas educacionais teriam de promover as condições necessárias à implementação desses ajustes, tanto no âmbito econômico quanto em relação aos aspectos políticos e sociais. Para Maués (2005, p. 8): 
As Reformas Educacionais, sendo uma forma de regulação social, poderão ter o papel não somente de realizar um ajuste no sistema social, de manter o equilíbrio, como podem servir de controle, na medida em que elas venham de cima para baixo, como é o caso em alguns países. Isto é, são os organismos governamentais que decidem o significado que devem tomar as reformas, a partir das relações que se estabelecem no contexto mundial, quer seja no aspecto político, econômico ou social. (MAUÉS, 2005, p. 8).

Essas reformas são abordadas em sua dimensão substantiva, na qual são apontados seus conteúdos ético-políticos e sua motivação ideológica, mas sua dimensão processual ganha relevo quando são abordados seus princípios organizativos e os aspectos relacionais, trazendo seus atores, principalmente representados na figura de Bresser-Pereira, ministro do então presidente Fernando Henrique Cardoso. É recorrente a ideia de que o passo fundamental para a elaboração da reforma do Estado brasileiro, como aponta, por exemplo, Savana Melo (2003, p. 1), “[...] foi a criação do Ministério da Administração e Reforma do Estado que, comandado por Bresser Pereira, lhe deu substrato. Através do Plano Diretor da Reforma do Estado - PDRE, o governo apresenta sua proposta à sociedade em 1995.

As reformas educacionais, promovidas a partir dos anos de 1990, são tomadas como reflexas a essa reorganização do Estado brasileiro e assumidas como premissa, de modo tendencial, para caracterizar a relação entre o lugar que a Educação ocupa no contexto desta reorganização produtiva e as decisões emanadas do Estado, assim como suas omissões, em prol das necessidades do capital.

De modo geral, a base sobre a qual se fundamentam as críticas às políticas educacionais recai sobre o modo de compreender a organização estatal e seus processos político-administrativos (identificados com o gerencialismo), repercutindo em seus diversos aspectos a conjugação desses elementos com aqueles relacionados ao ideário neoliberal e estabelecendo uma vinculação direta entre as necessidades do mercado, a submissão do Estado a essas necessidades, as consequentes reformas no aparelho de Estado e as reformas educacionais como parte desse processo.

Nesse conjunto de ideias que se entrelaçam, aparece outro traço que ajuda a formar um desenho mais abrangente acerca da concepção de Estado que circula nessa produção sobre política educacional. A concepção de Estado com função educativa aparece no estudo realizado por Dirce Freitas (2005), no qual são abordadas as funções pedagógica e normativa da avaliação da Educação Básica no Brasil. Em seu estudo, a autora toma como hipótese a ideia de que: 
[...] o Estado brasileiro, ao fazer a regulação via avaliação, teria operado uma ação educativa (formativa) por meio de um conjunto de medidas pedagógicas, encontrando nessas medidas um veio de sua própria consolidação e aperfeiçoamento, devido a propiciar aprendizagens relativas à gestão, à disciplina das relações federativas no setor educação e a promover mudanças culturais (valores, atitudes, comportamentos, representações) na esfera da relação Estado/sociedade/educação. (FREITAS, 2005, p. $5)$.

Percebe-se que há uma imbricação entre os atributos do Estado, como ente que regula, avalia, disciplina e, simultaneamente, promove ações formativas. A função reguladora do Estado é trazida em associação a processos pedagógicos stricto sensu (avaliação e currículo) e passa a incorporar o caráter regulador, não apenas no aspecto da aprendizagem escolar, mas também no que tange às práticas político-administrativas, pretendendo produzir mudanças que favoreçam seu funcionamento nos moldes em que se organiza e que corresponde, segundo Freitas (2005, p. 5):

[...] a um dado projeto estatal de intervenção social, vinculado a projetos hegemônicos na sociedade. Fortalecido por tal vínculo e, ao mesmo tempo, fortalecendo-o, o Estado central procurou construir a prevalência de seu projeto educacional sobre quaisquer outros da área, estabelecendo, para isso, um contexto de relações pedagógicas entre as unidades da federação e a União e entre esta e instâncias internacionais influentes na educação.

$\mathrm{Na}$ mesma trilha, que associa o caráter educador do Estado a seu traço centralizador e regulador, remontando às primeiras formulações liberais de Estado, Gilda Araújo (2007, p. 8) entende que:

Em meados do século XVIII a mudança no diagrama liberal no que diz respeito à questão social se fez presente no debate educacional, mas com alguns contornos bem específicos, pois à idéia [sic passsim] de Estado protetor foi acoplada a idéia de um Estado educador, de um Estado civilizador por meio das reformas educativas. Um Estado, portanto, com forte perfil centralizador e regulador visto que se impunha uma tarefa de "regeneração" da sociedade (BOTO, 1996).

Todavia, ao mesmo tempo em que o projeto emancipador da educação tinha um aspecto de conformação social, poderia resultar também em desejo de mudança na ordem estabelecida. Dessa forma, muitos filósofos iluministas discordavam da extensão da educação para o povo e outros, como Diderot, defendiam estudos diversificados como forma de preparação para variadas profissões, como uma etapa do processo de educação obrigatória e gratuita.

Pode-se dizer, que a base funcional desse sentido "regenerador" ligado ao atributo educador do Estado, tanto é assumida pelas interpretações neoliberais quanto pelas correntes que fazem críticas ao modelo capitalista de organização econômica e social. Se na interpretação neoliberal essa função ganha traços moralistas e utilitaristas, com o objetivo de educar a massa para a (e pela) moral burguesa e 
ainda capacitar os sujeitos para ocupação de postos no mercado de trabalho; na interpretação crítica o caráter "emancipador" (de fundo ético-político) é tomado como recurso estratégico para promover a conformação de uma "vontade geral" (na acepção gramsciana) favorável à transformação das relações sociais.

Acerca de outro aspecto, as relações de trabalho aparecem também como elemento importante na definição do conceito de capitalismo e mercado (na relação com o Estado), associando-os aos conceitos de competitividade, produtividade e responsabilização como predicativos identificados com uma organização estatal que seja eficiente e eficaz, na visão atribuída ao pensamento neoliberal, tido como fundamento para as ações gestoras do Estado. Esses conceitos aparecem de maneira recorrente, mas de modo pouco aprofundado, sendo eles mesmos também elementos importantes a serem discutidos tanto para a construção das políticas quanto na construção de um repertório analítico a ser aperfeiçoado. A tensão entre competitividade, produtividade e responsabilização, de um lado, e ineficiência, ineficácia e improdutividade atribuídas ao Estado, de outro, carece de estudo e aprofundamento, especialmente no que diz respeito aos aspectos administrativos, uma vez que parece ser consenso a ideia de que os aparelhos de Estado devam funcionar de modo adequado no sentido de desenvolver suas funções. Há que se encontrar um ponto de equilíbrio entre aquilo que não se configure como ineficiência, ou desperdício, do Estado no desempenho de suas funções e o que o neoliberalismo denomina de produtividade.

A utilização desses conceitos como forma de conferir atributos ao Estado funciona também como estratégia discursiva para, apontando a existência de seu traço interventor, regulador, educador, avaliador, financiador e empreendedor (também, esses, seus atributos), atribuir-lhe, tacitamente ou não, uma "natureza" autoritária, na sua forma neoliberal capitalista, identificada com a acepção de um Estado burguês.

As críticas feitas ao modelo neoliberal que, pela denúncia dos trabalhos, estabelece as diretrizes das ações de Estado, pouco exploram a capacidade operativa da burocracia e sua suposta independência política stricto sensu em relação às pressões sociais e do capital. A questão sobre até que ponto o poder da burocracia estatal reage às pressões dos agentes do capital e em que medida tal burocracia é ocupada por essa parcela da sociedade seria um elemento importante a ser debatido. Cabe, portanto, a pergunta sobre quais seriam os embates travados no interior do poder público naqueles setores considerados estratégicos pela Reforma Bresser-Pereira, por exemplo. Dessa decorreria outra questão, sobre qual seria a inclinação político-ideológica da burocracia estatal, constituída por funcionários de carreia e 
bem remunerados (tomando-se de modo esquemático um dos preceitos dessa reforma empreendida no Estado brasileiro). Esse debate poderia aprofundar o conhecimento sobre as relações entre Estado e capital e revelar o grau dessa “independência” do aparelho burocrático (pressuposto pelo neoliberalismo) e os mecanismos de construção de consenso e hegemonia na formulação das políticas educacionais, bem como ofereceria elementos mais consistente para a crítica.

O debate sobre as relações entre Estado e a denominada sociedade civil permeia boa parte dos trabalhos quando se trata de analisar aspectos relacionados à participação: conselhos, controle social, agentes sociais diversos, sobretudo aqueles que representam o capital, nos seus movimentos para induzir, dimensionar e delimitar as políticas públicas. São, portanto, estudos que revelam aspectos relativos a dimensões que discutem processos, relações, instituições e sujeitos, estabelecendo um sentido instrumental a essas políticas em relação ao poder que a sociedade civil exerce sobre o Estado, por meio daqueles agentes do capital.

A análise dos conteúdos e sentidos atribuídos ao termo e a análise da categoria sociedade civil é pouco explorada em suas nuances e possibilidades de apropriação ideológica, tanto na construção da concepção de Estado em debate quanto nas suas implicações para a elaboração de um constructo teórico para a análise das políticas públicas.

Na perspectiva de conceituar Estado e sua relação com as políticas educacionais, principal foco das preocupações do GT - 5, as acepções trazidas apontam para uma convergência: a relação entre mercado e Estado ancora o debate, tanto para estabelecer seus papeis quanto para asseverar a hegemonia do capital em relação ao trabalho, na tomada de decisões que ordenam essas políticas. Essa convergência, aparentemente óbvia, traz uma questão acerca da natureza teórica da crítica realizada ao Estado.

Parece haver um consenso em torno da crítica a alguns fenômenos relacionados ao capitalismo. Inúmeros trabalhos deixam entrever, tanto nos diagnósticos quanto nas interpretações neles fundamentados, que o capitalismo tem produzido efeitos nocivos a grande parte da sociedade civil e ao Estado na realização de suas funções. Neoliberais e seus críticos, de alguma forma, concordam que tanto o capitalismo quanto o Estado passam por intenso momento de, pelo menos, instabilidade. A forma de organizar os aparelhos estatais, sua relação (subserviente ou reativa) com o capital, a aplicação de recursos públicos (“capital”), todos esses elementos são objeto de crítica.

A posição neoliberal apontada como disparadora das concepções que orientam as políticas educacionais são colocadas de modo claro. Há, todavia, uma falta de definição, claramente posta e 
capaz de demonstrar-se como tendência, sobre qual o lugar ocupado por essas críticas ao capitalismo na acepção neoliberal. De um lado parecem estar aqueles que tomam esses objetos de crítica como resultantes de um processo de reorganização do sistema capitalista, portanto elementos que estão mais identificados como conjunturais. Nesse caso, as críticas se dirigem às consequências desse momento, aos efeitos depredadores desse movimento de "ajustes". De outro lado estão as críticas que apontam para o caráter estrutural desses mesmos elementos, que são tomados não como consequências desses movimentos, mas como maneira pela qual se expressa o modo de organização do capitalismo. Nesse caso, a crítica se dá na perspectiva de que esses "ajustes" fazem parte da essência (no sentido marxiano de expressar aquilo que é o capitalismo em sua realidade concreta), portanto lhe são estruturais, sem negar-lhe também, todavia, o caráter conjuntural e sua singularidade história.

Por fim, para a Educação, essa contradição aparece como mote para a necessidade do esclarecimento acerca da função educadora do Estado: o que deve caracterizar o projeto educador do Estado brasileiro? O Estado deve educar para permanência, para promover mudanças (ajustes) que minimizem os "efeitos" do capitalismo ou para a transformação, portanto, para a superação do capitalismo?

Essa é uma questão que revela uma contradição: há um posicionamento de ordem ético-política que ganha expressão na crítica ao rumo tomado pelo Estado brasileiro no tocante às reformas que vem implementando, ao mesmo tempo em que, mantida a base funcionalista na qual se sustenta o debate sobre a relação entre Estado e políticas educacionais, não fica claro o posicionamento acerca da necessidade de superação do capitalismo como forma de organização das relações político-econômicas e sociais em que se concretizam essas reformas.

O debate sobre políticas educacionais não se esgota na produção aqui estudada, porém esses trabalhos refletem boa parte das pesquisas desenvolvidas nas universidades e trazem as temáticas centrais que em geral são tratadas em outros espaços acadêmico-científicos. A diversidade expressa por meio da adoção de várias correntes teórico-metodológicas que circulam no meio acadêmico-científico, em especial aquelas mobilizadas para tratar dessas políticas, também tem se mostrado um problema, na medida em que provoca, pela dificuldade de se formar uma base consolidada de conceitos e categorias, uma dificuldade em se estabelecer um debate capaz de produzir maior acúmulo.

Sendo assim, as carências e lacunas aqui apontadas, das quais não escapa o presente trabalho, são tomadas menos como críticas à produção acadêmico-científica analisada e mais como um desafio a ser enfrentado pelos pesquisadores no intuito de compreender e produzir intervenções concretas, 
através das ações políticas que consolidem o processo de ocupação de espaços capazes de transformar a sociedade.

Nota

${ }^{1}$ Não se apresenta de forma clara no período aqui analisado uma tendência acerca da crítica à possibilidade de uma Terceira Via, como alternativa ao capitalismo, embora existam trabalhos que versem sobre o tema. (SILVA, 2004; LÉLIS, 2005, 2007).

\section{REFERÊNCIAS}

ARAUJO, Gilda Cardoso de.Estado, direitos de cidadania e direito à educação: do programa ao diagrama. In: REUNIÃO ANUAL DA ASSOCIAÇÃO NACIONAL DE PESQUISA E PÓSGRADUAÇÃO EM EDUCAÇÃO, 30., 2007, Caxambu. Anais... Caxambu, MG: ANPEd, 2007.

BOTO, Carlota. A escola do homem novo: entre o Iluminismo e a Revolução Francesa. São Paulo: UNESP, 1996.

CARVALHO, Celso do Prado Ferraz de. Políticas educacionais e disputa pela hegemonia: a ação política do Instituto Euvaldo Lodi. In: REUNIÃO ANUAL DA ASSOCIAÇÃO NACIONAL DE PESQUISA E PÓS-GRADUAÇÃO EM EDUCAÇÃO, 30., 2007, Caxambu. Anais... Caxambu, MG: ANPEd, 2007.

CATANI, Afranio Mendes; OLIVEIRA, João Ferreira de; DOURADO, Luiz Fernandes. Mudanças no mundo do trabalho e reforma curricular dos cursos de graduação no Brasil. In: REUNIÃO ANUAL DA ASSOCIAÇÃO NACIONAL DE PESQUISA E PÓS-GRADUAÇÃO EM EDUCAÇÃO, 23., 2000, Caxambu. Anais... Caxambu, MG: ANPEd, 2000.

FREITAS, Dirce Nei Teixeira de. A avaliação da Educação Básica no Brasil: dimensão normativa pedagógica e educativa. In: REUNIÃO ANUAL DA ASSOCIAÇÃO NACIONAL DE PESQUISA E PÓS-GRADUAÇÃO EM EDUCAÇÃO, 28., 2005, Caxambu. Anais... Caxambu, MG: ANPEd, 2005.

GIL, I-Juca Pirama Camargo. Conselho do FUNDEF: uma história de atribuições esvaziadas.In: REUNIÃO ANUAL DA ASSOCIAÇÃO NACIONAL DE PESQUISA E PÓS-GRADUAÇÃO EM EDUCAÇÃO, 31., 2008, Caxambu. Anais... Caxambu, MG: ANPEd, 2008.

LÉLIS, Úrsula Adelaide de. A materialização das políticas do "terceiro setor", na educação brasileira, no contexto de "(contra-)reforma" do Estado. In: REUNIÃO ANUAL DA ASSOCIAÇÃ̃O NACIONAL DE PESQUISA E PÓS-GRADUAÇÃO EM EDUCAÇÃO, 30., 2007, Caxambu. Anais... Caxambu, MG: ANPEd, 2007.

LELIS, Ursula Adelaide. Políticas e práticas do terceiro setor para educação no contexto de "(contra)reforma" do Estado. In: REUNIÃO ANUAL DA ASSOCIAÇÃO NACIONAL DE PESQUISA E PÓS-GRADUAÇÃO EM EDUCAÇÃO, 28., 2005, Caxambu. Anais... Caxambu, MG: ANPEd, 2005. 
MAUÉS, Olgaíses Cabral. O trabalho docente no contexto das reformas. In: REUNIÃO ANUAL DA ASSOCIAÇÃO NACIONAL DE PESQUISA E PÓS-GRADUAÇÃO EM EDUCAÇÃO, 28., 2005, Caxambu. Anais... Caxambu, MG: ANPEd, 2005.

MELO, Savana Diniz Gomes. Para onde convergem a Reforma Administrativa e a Reforma da Educação Profissional? In: REUNIÃO ANUAL DA ASSOCIAÇÃO NACIONAL DE PESQUISA E PÓS-GRADUAÇÃO EM EDUCAÇÃO, 26., 2003, Poços de Caldas. Anais... Poços de Caldas, MG: ANPEd, 2003.

NEVES, Lucia Maria Wanderley. As reformas da educação escolar brasileira e a formação de um intelectual urbano de novo tipo. In: REUNIÃO ANUAL DA ASSOCIAÇÃO NACIONAL DE PESQUISA E PÓS-GRADUAÇÃO EM EDUCAÇÃO, 27., 2004, Caxambu. Anais... Caxambu, MG: ANPEd, 2004.

PERONI, Vera Maria Vidal. O Estado brasileiro e a política educacional dos anos 90. In: REUNIÃO ANUAL DA ASSOCIAÇÃO NACIONAL DE PESQUISA E PÓS-GRADUAÇÃO EM EDUCAÇÃO, 23., 2000, Caxambu. Anais... Caxambu, MG: ANPEd, 2000.

SANTIAGO, Anna Rosa F. A viabilidade dos PCN como política pública de intervenção no currículo escolar. In: REUNIÃO ANUAL DA ASSOCIAÇÃO NACIONAL DE PESQUISA E PÓSGRADUAÇÃO EM EDUCAÇÃ̃, 23., 2000, Caxambu. Anais... Caxambu, MG: ANPEd, 2000.

SILVA, Joyce Mary Adam de Paula e. Política educacional e cultura das organizações no Brasil. In: REUNIÃO ANUAL DA ASSOCIAÇÃO NACIONAL DE PESQUISA E PÓS-GRADUAÇÃO EM EDUCAÇÃO, 27., 2004, Caxambu. Anais... Caxambu, MG: ANPEd, 2004.

SIQUEIRA, Ângela Carvalho de. O novo discurso do Banco Mundial e o seu mais recente documento de política educacional. In: REUNIÃO ANUAL DA ASSOCIAÇÃO NACIONAL DE PESQUISA E PÓS-GRADUAÇÃO EM EDUCAÇÃO, 24., 2001, Caxambu. Anais... Caxambu, MG: ANPEd, 2001.

VOLPE, Geruza Cristina Meirelles. Público, mas nem tanto; crise, mas nem tanta: sobre fundos públicos e crise (fiscal) do Estado (capitalista). In: REUNIÃO ANUAL DA ASSOCIAÇÃO NACIONAL DE PESQUISA E PÓS-GRADUAÇÃO EM EDUCAÇÃO, 30., 2007, Caxambu. Anais... Caxambu, MG: ANPEd, 2007. 
The conception of the State in the debate on educational policy: an analysis of the work presented in GT5 ANPEd (2000-2010)
El concepto de Estado en el debate sobre la política educativa: un análisis de los trabajos presentados en GT5 ANPEd (2000-2010)

\section{Resumen}

El objetivo de este trabajo es presentar un análisis de la concepción del Estado que subyace en el debate que se ocupa de las políticas educativas en Brasil. El texto forma parte de los resultados de la investigación dirigida a identificar los principales rasgos teóricas que caracterizan la producción referenciado por la Asociación Nacional de Estudios de Posgrado e Investigación en Educación ANPED través del GT5 - Política de Estado y de la Educación entre 2000 y 2010.

Palabras clave: Estado. Políticas educativas del Estado. La epistemología política.

Enviado em: 5/8/2015

Aprovado em: 15/9/2016

E-mail: armandoarosa@yahoo.com.br 